\title{
Stakeholders' Perception About the Effectiveness of Renewable Energy Subsidy in Nepal: A Review of Biogas Subsidy
}

\author{
Ashma Vaidya \\ Centre for Rural Technology, Nepal \\ Corresponding Email: ashmavaidya@gmail.com
}

\begin{abstract}
:
Due to sustainability and climate change concerns associated with fossil fuels, renewable energy (RE) is increasingly being recognized as crucial link between energy access and sustainable development. Growing interest in RE has led many countries to adopt different strategies to promote its growth. Subsidy in various forms is one of the common measures governments around the world have used to support the production and to encourage the use of RE technologies. Renewable energy sector in Nepal is also largely driven by RE subsidies, primarily targeted at potential users. While many argue that subsidy played a major role in the promotion and uptake of RETs, there is little knowledge on the differential impact RE subsidies have had on different stakeholders and actors in the RE sector. Knowledge about broader impact of RE subsidy, its relevance to different RETs and its effectiveness in achieving sustainability of the sector also remains largely fragmented. In order to devise strategies to overcome barriers in the development of RE sector in Nepal, it is important to fill these knowledge gaps. It is also important to better understand challenges and opportunities. To this end, this study uses qualitative research method to draw knowledge from different stakeholders about the effectiveness of renewable energy subsidy policy in Nepal. The primary focus of this study is biogas subsidy that has been in place since the 1990s. The study reveals that the effectiveness of RE subsidy is a function of various factors such as users' awareness about RET benefits, government policy and provisions, cost-effectiveness of the technology, after-sales-services, long-term access to RE technologies and services etc. The general consensus is that RE subsidy so far has primarily benefited better-off households than the low-income populations. It was also revealed that, without subsidy or some kind of financial intermediation, access of poor farmers to biogas technology is likely to remain a challenge. The high upfront cost of the technology was frequently cited as one of the biggest barriers in the market-led dissemination of biogas technology (particularly the one being promoted by the Government of Nepal). This highlights the need for improvement in resource (land, raw material for its construction and operation) and cost efficiency of the technology for it to remain economically viable for farming communities, to whom the technology might have the greatest utility. Better measures and communication strategy are needed to make targeted subsidies and relevant information about policy mandates and provision accessible to the grass roots.
\end{abstract}

Keywords: Renewable Energy, Renewable Energy Subsidy, Biogas, Energy Subsidy

\section{Introduction}

Although the use of renewable energy (RE) subsidy as a tool to stimulate demand now has a long history in Nepal, its impact on different levels of the society is yet to be established. Reports and assessments of the past RE programmes involving the use of subsidy have suggested that subsidy policy is one of the reasons for the increased initial adoption of RE technologies, but may also have distorted the market for independent RE entrepreneurs in Nepal. In 2007, annual sales of solar home systems plummeted following the decline in the subsidy amount as a result of insufficient Renewable Energy Fund for subsidy [1]. On the consumer side, despite the availability of a range of RETs (in terms of size, efficiency and functions), subsidy is believed to have encouraged the sales of only specific kinds of RETs. More recently, studies have suggested that subsidy policies are increasingly serving the better-off population than the ones that genuinely need subsidy for their access to RETs $[2,3,4,5]$. Furthermore, subsidy is believed to have instilled a sense of entitlement among rural population, thereby suppressing the demand for RE technology when the subsidy is not available [6]. Conversely, there is a general consensus that there is little motivation for RE entrepreneurs to expand their services to rural poor populations without RE subsidy. Little is known about its significance and impact on the end beneficiaries.

In this paper, the author investigates the perception of different actors within the subsidy delivery system (including the end-beneficiaries) about the effectiveness of RE subsidy in Nepal. The focus of this study is subsidy on biogas technology, which is why the study findings may not be generalized across all sub-sectors of renewable 
Stakeholders' Perception About the Effectiveness of Renewable Energy Subsidy in Nepal: A Review of Biogas Subsidy

energy. Some views elicited from key informants working on the national level, however, are for larger RE landscape of Nepal. This study is meant to provide an elevated view of RE subsidy and its effectiveness in meeting the overall objective of the subsidy policy.

\section{Energy Subsidy: A general overview}

According to the International Energy Agency (IEA), energy subsidy may be referred to as any kind of government support aimed at lowering the cost of energy usage by incentivizing the production of energy or through price reduction for final consumers [7]. Some of the commonly used forms of energy subsidy are tax incentives, subsidy on technology prices, subsidy on energy prices, soft loans, or tax expenditures. While these are explicit forms, subsidy may also occur in implicit forms such as through investment in research and development, or infrastructure development [8]. Regardless of where and how subsidy is implemented, the function of subsidy is essentially to fix market failures, and to enhance social welfare. From the social welfare point of view, subsidy on improving energy access rather than on the operation cost or energy use is widely viewed as more justifiable and sustainable $[9,10]$.

\section{Progress in RE Policies in Nepal}

Nepal adopted a programmatic approach to the promotion and development of renewable energy sector since the 1992-1996 development plan period and has continued to do so until today [11]. The establishment of Alternative Energy Promotion Centre (AEPC) in 1996 as a focal government agency contributed to streamlining renewable energy development in Nepal. Historically, making renewable energy technologies accessible to rural population has been the major thrust of renewable energy policies of Nepal. Below, the author discusses key RE policies that guide the RE sector in Nepal.

\subsection{Rural Energy Policy 2006}

The Rural Energy Policy (REP) 2006, one of the first policy documents on renewable energy in Nepal, states ensuring access to 'clean, reliable and appropriate energy in the rural areas' to achieve rural poverty reduction and environmental conservation as its major goal. It highlights the government's interest to support economic activities in rural areas through the development of biogas, mini and micro hydro, improved water mills and solar energy (PV and thermal) systems. It also acknowledges the need for representation of women and underprivileged ("marginalized", “disadvantaged" and "backward") groups in RE-related user and community organizations. It also promises a special arrangement for low-income and 'backward' groups. However, much of the language pertinent to subsidy and, gender equity and social inclusion (GESI) in the document is rather vague and subject to varying interpretation. The Article 5.1 of the document states that "Subsidy will be arranged by classifying Village Development Committees (VDCs) based on poverty, remoteness, dalit and backward caste and tribes', but it fails to acknowledge the heterogeneity in populations within VDCs. The document emphasizes the participation of local bodies, community-based organizations, users' groups, cooperatives and private sectors in leading the RE sector development. However, little emphasis is given to the inclusion of 'people without voice' (i.e. women and underprivileged people) in the actual statement of policies. Out of 19 policies that the document lists out as measures to achieve the overall objective, women are brought up only once in relation to promotional activities and there is no mention of historically marginalized or underprivileged groups [12].

\subsection{Renewable Energy Subsidy Policy 2016}

In 2009, the Government of Nepal drafted its first Renewable Energy Subsidy Policy. The focus of this section is the latest version of the Renewable Energy Subsidy Policy of Nepal drafted in 2016, and the Renewable Energy Subsidy Delivery Mechanism 2016 [13]. The two policy documents provide comprehensive guidelines for institutional arrangements, criteria for RE subsidy, and subsidy delivery mechanism.

The main objective of RESP 2016, as it states, is "to reduce dependence of the people on traditional and imported fuels, and concomitantly improve livelihoods and create employment opportunities particularly for rural population". It is different from other policy documents discussed here, in that it is explicit about the provision it has for "single women, low income, natural disaster victims and socio-economically disadvantaged groups". Subsidy under RESP is designed based on technology type, least cost to energy output, geographical location and targeted beneficiaries. It also provides a clearer definition of eligible group ${ }^{1}$ for targeted subsidies leaving little space for inconsistency and confusion.

\footnotetext{
${ }^{1}$ i.e. Targeted beneficiaries: women-led households with dependent children, earthquake victims from earthquake-affected districts, endangered indigenous community identified by GoN and Dalit.
} 
The RESP 2016 offers not only direct cost reductions on RETs but also other forms of financial support as measures to facilitate the growth of RETs (credit-line and credit guarantee schemes for financial institutions to encourage investment in renewable energy; financial support for detail feasibility studies of RE projects/systems, etc.). While the previous subsidy policy documents focused mostly on subsidizing the technology cost for end-consumers, recent RESPs demonstrate support also to other actors in the RE value chain (such as financial institutions, RE-based enterprises, community and private entities involved in power generation). Additionally, the RESP 2016 promotes productive energy uses and integrative approach to improve rural economy. While there is still a room for improvement (e.g. limited focus on leveraging market potentials), the RESP 2016 suggests that RE governance in Nepal is moving along a sustainable trajectory.

\subsubsection{Subsidy on Biogas}

Table 1: Subsidies on Biogas plants [13]

\begin{tabular}{|l|l|l|l|l|}
\hline \multirow{2}{*}{ Eligible Units } & \multirow{2}{*}{$\begin{array}{l}\text { Capacity/ } \\
\text { Scale }\end{array}$} & \multicolumn{3}{|l|}{ Subsidy Amount (NRs.) } \\
\cline { 3 - 5 } & Mountain & Hill & Terai \\
\hline Domestic $^{*}$ & $2 \mathrm{~m}^{3}$ & 25,000 & 20,000 & 16,000 \\
\hline & $4 \mathrm{~m}^{3}$ & 30,000 & 25,000 & 20,000 \\
\hline & $\geq 6 \mathrm{~m}^{3}$ & 35,000 & 30,000 & 24,000 \\
\hline $\begin{array}{l}\text { Waste-to- } \\
\text { energy based }^{* *}\end{array}$ & Commercial & & $24,000-$ & $20,000-$ \\
& Institutional & & $68,000^{\#}$ & 30,000 \\
\hline & Communal & & 54,000 & 57,000 \\
\hline & Municipal & & $\begin{array}{l}\text { Up to } \\
240,000\end{array}$ & $\begin{array}{l}\text { Up to } \\
200,000\end{array}$ \\
\hline
\end{tabular}

*Additional subsidy of 10 per cent of the total subsidy is provided to target beneficiaries

**Additional subsidy is provided for electricity generation per $\mathrm{kW}$

\#Varies depending on capacity of the plant

Biogas plant remains one of the important RETs for many rural farming communities of Nepal. Biogas Programme has been widely touted as one of the flagships RE programmes of Nepal. Since the 1990s, more than 300,000 biogas plants have already been installed across the country, making Nepal the third leading country in the world in biogas installations. Consumer financing/subsidy and the promotion of biogas as multipurpose technology (as a source of cooking fuel, energy lighting, manure, and as a technology for toilet and agro-waste management) are often cited as important factors contributing to the success of biogas programmes in Nepal.
According to the RESP 2016, subsidy for biogas technology is valid for GGC 1990 model, its improved version and "other latest efficient models of various capacities to serve the homes, public institutions, commercial enterprises and communities" [13]. The policy also promotes domestic biogas as a measure for solid waste management in urban areas. Subsidy on biogas plants varies for different sizes, types (domestic versus waste-to-energy based) and for different geographical regions (See Table 1).

\section{Method}

The research objective was to understand the utility and effectiveness of biogas subsidy at the grass roots and its delivery mechanism through the eyes of key actors directly associated with the RE subsidy delivery mechanism. The study involved in-depth interviews and focus group discussion with key actors representing different stakeholder groups: RE-related government agency, biogas-related NGOs, biogas companies (Kavrebased) and biogas users based in Panchkhal and Mandan Deupur areas of Kavre district. Interviews were conducted in Nepali, i.e. local language. All conversations were recorded, and later transcribed and translated into English for further analysis. Consent from each study participant was obtained in written or orally prior to the administration of any ethnographic tools.

\section{$5 \quad$ Findings}

Findings of this study have been arranged under different sub-headings to represent perceptions of different stakeholder groups about renewable energy subsidy policy (biogas subsidy in particular) and subsidy delivery mechanism.

\subsection{Perception of government agencies}

From almost zero percent share of RE in total energy consumption in 1995, RE today, accounts for over 3 percent of the total energy consumed in Nepal [14]. The government has integrated RE in Periodic Plans and Annual Budget Plan as one of the priority sectors, and the public expenditure in the sector has also been increasing every year. Multi-stakeholder partnership or more specifically, public-private partnership approach has played a key role in facilitating the growth of RE sector in Nepal. Subsidy may have played a role, but only partly as subsidy policies have always required end-beneficiaries to contribute to the total cost of RETs either in cash or in kind. 
The government provides subsidy through RE companies/suppliers after the installation of the technology. Consumers may not be able to receive the subsidy if the RETs are bought from non-qualified suppliers.

\subsubsection{Subsidy delivery mechanism}

The subsidy delivery mechanism involves a rigorous verification process. There have been some improvements made in the past. For example, the policy now requires Central Renewable Energy Fund to disburse the subsidy amount to the concerned companies within 45 days after it receives the application. Since June 2017, the government has started online application system to claim subsidy for household systems. The system allows the applicants (companies) to track the application and see its status online from the day application is filed till the subsidy is disbursed. Community and institutional plants have not yet been put into online database system. According to one participant, most of the RE companies are located in district headquarters with access to the Internet, so every company currently is using the online subsidy application system. The government has not been able to digitalize the data entry system in the field but every procedure that needs to be completed after data reach the headquarters has been digitalized. Efforts are being made to develop a data entry system, which can take in data from the field through offline centralized data entry system for greater efficiency and transparency of the process.

\subsubsection{Target subsidy}

The current RE subsidy policy has set different subsidy amounts contingent on geographic locations (or remoteness), energy sources (such as solar, hydro, biomass), capacity or size (as for biogas plant and solar photovoltaic home systems), purpose (Institutional solar PV systems), and technology types (as for different types of cookstoves). The policy also has a provision of additional subsidy for "targeted beneficiary groups that include women-led households with dependent children, earthquake victims from earthquake affected districts, endangered indigenous community identified by the Nepal government and Dalit" [13]. For some technologies, there is a provision for up to 80 percent subsidy. Differential purchasing capacity of populations in different districts has also been taken into account while determining subsidy amount for different technologies and geographical locations. However, there seem to be a lack of mechanism to subsidize the RE cost for lowincome populations in given districts. The study participants acknowledged the need for the government to improve target subsidy policies to make them more exclusive for deprived and marginalized families, and to ensure the sustainability of the RE sector.

According to a participant, as accessible areas are gradually becoming saturated with RE technologies, demand for subsidy is now coming from more rural and remote areas. In remote areas, while the purchasing power of people is lower, the cost of technologies increases due to transportation. Given the number of population that are still deprived of access to clean and modern energy technologies which remains huge, and given the fact that majority of the energy deprived population earn below the poverty line of USD 1.9/day, targeted subsidy is crucial at the moment to allow them livelihood opportunities.

The policy needs to clearly distinguish between regular subsidy and targeted subsidy. For areas that are not yet electrified and have majority of the population poor and vulnerable, it is important to implement targeted subsidy and RE programmes. Regular subsidy can be removed for some of the technologies, while it may still be needed for some RETs with higher upfront cost but larger social benefits. In order to ensure optimum benefit from subsidy policies, subsidy should be linked with the energy output. Regular subsidy will still be needed to improve energy access in many areas where the populations are predominantly poor and marginalized. On the other hand, targeted subsidy will be necessary to ensure equitable access to energy within heterogeneous communities.

\subsubsection{Low-income communities}

Policies are being revised to empower and enable poor communities to benefit from RETs and their various implications. Since 2012, government has been promoting energy-based enterprise development. The government has also realized the need to integrate productive uses and enterprise development into the efforts to promote $\mathrm{RE}$ technologies, to ensure the access of poor population to finance mechanism and RETs. RETS have also been contributing to the improved livelihood and increased income of rural communities. As for example, a community-owned $23 \mathrm{~kW}$ micro-hydro project in Nuwakot used to earn small amount of money every month by selling off-grid electricity to the rural households. Recently, with advocacy and technical support from the AEPC, the plant could be interconnected to the central grid, which has created numerous opportunities for low-income community to improve their livelihood.

\subsubsection{Financing RETS}


Access to financial institutions is lacking in many targeted areas. Banks have shown little interest in investing in RE sector, primarily because RE remains a sector with greater positive externalities but little profit. Perceived risk associated with financing RETs is higher than it is for other lucrative items. There is currently no dedicated fund allocated for credit financing. Earmarking funds for credit financing to ensure lower interest rate for RE projects may reduce the risk for financing institutions and encourage them to invest more in RETs in rural areas. Other alternatives could be to promote service-based pricing systems or fee-for-service ${ }^{2}$ modality, to reduce the cost of access to RE technologies for low-income households.

\subsubsection{Subsidy versus market-led dissemination}

Although the government intends to move away from subsidy-driven to credit based financing of RETs, it lacks strategies to achieve that. There are a number of challenges to pursue this transition, most important being the historical use of subsidy as an important promotional tool for stimulating demand for RETs. It is not economic for the government to keep subsidizing RETs.

Over the years, cost of solar energy technologies has sharply declined as a result of competition among national players, and the worldwide decline in the cost of solar technologies. However, the marginal cost of production for technologies such as micro-hydro and biogas technologies are less likely to decline over time due to two key reasons: i) they involve high human labor for construction in rural areas, the cost of which has increased over time ii) their construction usually entails customization of the technology based on the geotechnical context. For such technologies, output needs to be maximized by promoting productive uses of energy to make them economically viable.

\subsubsection{Impact assessment and monitoring}

The RE subsidy policy is revised regularly to incorporate learning from past experiences, feedback from different stakeholders and also to accommodate any changes in market context. There is a mandatory provision of thirdparty monitoring for renewable energy plants. The final installment of the subsidy amount is paid to the RE suppliers only after the final verification of the technologies and services are completed. During this monitoring process, the third party seeks feedback from the users, monitors the condition of the technology and assesses users' satisfaction. In case of micro-hydro, there is a provision for public hearing before and after the installation of the plant to collect feedback from the public about the project. Impact study has also been institutionalized; however, impact study part of the institution has not been very strong.

\subsection{Non-government actors in biogas sector}

Non-governmental organizations represented in this study are responsible for capacity building of biogas companies, quality control, promotion, database management, networking; testing, site verification of biogas plants etc. Most of the actors in biogas supply chain argue that government can reap multiple social and environmental benefits from biogas plants, for its investments in biogas subsidy. Unlike most of other renewable energy technologies, biogas technology addresses multiple rural development issues, such as energy (mainly for lighting and cooking), women drudgery, empowerment, health, agriculture (bio slurry, manure), carbon emission reduction, waste (toilet, agricultural, kitchen wastes) management, cleanliness and sanitation, environmental protection, etc. However, high upfront cost of installing a biogas plant remains a challenge for low income farming communities to own a plant.

\subsubsection{Subsidy policy and delivery mechanism}

The government lacks a mechanism to convey or communicate policy mandates and provisions to the grassroots, which is why many populations have not been able to benefit from the subsidy policies. Otherwise, renewable energy policy in Nepal may be viewed as progressive. During 1997 when the biogas technology had just started to grow in popularity, government only had 10 percent of share in the total subsidy provided on biogas technology (rest used to be covered by foreign aids), while today 100 percent of subsidy provided to the household biogas technology is covered by the government suggesting the government's ownership of the Biogas Programme.

Biogas companies have to pre-finance the technology; generally, they borrow money from banks ${ }^{3}$ at high interest rate to construct a biogas plant. Subsidy delivery process has been slow and the subsidy is disbursed only after the technology installation is verified. The lengthy process puts further pressure on biogas companies. While biogas

\footnotetext{
${ }^{2}$ Under "fee-for-service" model, a customer pays regular fees for the use of a renewable energy system that is owned, operated and managed by a cooperative or a private service provider or a supplying company.

${ }^{3}$ Biogas companies often turn to microfinance if they need to borrow small amount, and commercial banks if the need is for large loan amount.
} 
companies have to bear all the cost of biogas installation until the subsidy amount is disbursed, the burden of transaction and transportation costs are put on the shoulders of biogas users.

\subsubsection{Target subsidy}

Target beneficiaries who could not install biogas plants while they had the opportunity to benefit from the subsidy despite their eligibility to apply for, will likely not be able to own the technology if the subsidy is removed. There is a general consensus that subsidy on biogas technology is crucial for enabling and increasing its accessibility for rural poor communities. Most of the people who are still into farming in rural areas are generally poor and do not already have biogas in their homes. Removing subsidies from biogas technology will further diminish their chance to benefit from the technology.

Many argue that subsidy should be increased to reach to the population with limited purchasing capacity. Many poor farming households eligible to have a biogas plant in their homes are using agriculture loan to practice subsistence-type farming. Consumer financing may only add to their burden if the subsidy programme is transformed into a credit financing system. Biogas technology should be promoted as a crosscutting measure and its multiple benefits should be conveyed to the potential consumers. Biogas for cooking should be promoted as a co-benefit of the system, and the technology should be integrated into agro-based livelihood programmes to improve the utility of subsidy programmes and financing schemes.

\subsubsection{Effectiveness of RE subsidy}

Historically, high-income and upper middle-income households from farming communities in rural areas have been the key beneficiaries of the initial phases of renewable and rural energy programmes in Nepal. For target-driven renewable energy dissemination projects, high and middle-income groups are often the low hanging fruits with better access to information, finance and resources to adopt newer technologies. Similarly, these groups are the ones who have benefitted more from the 'blanket' subsidies' on all renewable energy technologies. Therefore, while RE subsidy may have been impactful in reducing the rural-urban energy divide, more targeted subsidies may be important to ensure rich-poor energy divide in rural farming communities. Assessing the impact of RE projects and subsidy programmes on the ground is challenging because of a lack of system for economic valuation of multiple benefits of the technology at different levels of the society. Many in rural areas take the benefits of biogas technologies for granted often leading to undervaluation of the technology.

\subsection{Biogas companies}

Currently, there are over 100 biogas companies registered as pre-qualified companies for the construction and promotion of domestic biogas plants. It is to pre-qualified companies that subsidy on biogas plant for endbeneficiaries is disbursed to post installation of a biogas plant.

\subsubsection{Subsidy delivery mechanism}

Many study participants representing pre-qualified biogas companies suggested that the process of subsidy delivery is too long and lacks transparency. They also suggested that it is difficult to track application status from their base districts as the Centre is located in Kathmandu. More recently though (since June 2017), the process has been digitalized by setting up an online application system for household RE subsidy. However, companies argue that while this has largely reduced the cost and has made the process more efficient and transparent, the time lag between the subsidy application and the disbursement dates has not reduced by much.

Consumers are required to contribute partly to the total cost of biogas plant in the form of labor and construction materials such as sand, gravel and water. Although consumer and biogas company sign an agreement prior to starting the work, companies often face difficulty in completing the work on time due to delay by consumers in preparing the construction materials. This in turn can affect the company's ability to meet the yearly target on time. Inability to meet certain percent of the set target stated in the yearly plan can lead to the termination of prequalification of the companies. Therefore, companies prefer to build biogas for consumers who can readily prepare construction materials and required labor for the installation of biogas at their houses.

\subsubsection{Limitation of the biogas sector}

Most of the domestic RE technologies (such as biogas and solar technologies) have long life, which means the biogas market in one location quickly saturates and repeat clients are not common for RE vendors and companies. This is why companies have to constantly look for newer clients, stay mobile, and move their services to newer areas if they are to remain in the business. This is one of the reasons why companies are reluctant to remain available for repair services in one area, after the warranty period. It is also not cost-effective for biogas companies to travel long distances to address a demand or issue (biogas-related) of 
one client; they often collect multiple demands from one community before they decide to move there to construct biogas plants.

RE companies need to pre-finance the RETs, and the payments are made to them by the Central Renewable Energy Fund after the technology is installed and verified. $\mathrm{RE}$ companies generally rely on local micro-financing institutions for small loan amount, but have to go to commercial banks usually based in Kathmandu or other nearest cities for large sum of loan amounts. Many participants representing biogas companies suggested that if the government could provide soft loans for biogas technologies, it would lower the risk for companies and also the cost of the technology for consumers. Lack of fund to invest has been a huge hurdle for biogas companies. In some areas, labor and other human resource are available and demand is increasing as well. However, due to a lack of working capital, companies have not been able to build as many biogas plants as there is a demand for.

\subsubsection{Biogas price and subsidy}

Subsidy amount has not been able to keep up with the increased cost of biogas construction. One of the points highlighted at a focus group meeting was that, a number of biogas companies are struggling to survive due to a lack of investment. People who are aware of the benefits of biogas know that it's a one-time investment and energy can be generated in their backyard continuously for a number of years using agricultural, animal and toilet wastes. However, for many the high up font cost of a biogas plant is an important factor to not prefer the technology. Therefore, subsidy may be important to encourage initial adoption of the technology.

The efficiency of the technology promoted through the subsidy programme has more or less remained the same for the past 25 years. Biogas companies argue that the promotion of private sectors and market-led dissemination of renewable energy technologies could drive the improvement in the technology. Conversely, they also suggest that biogas should be viewed differently than other decentralized off-grid technologies. A lack of adequate number of technicians and masons in the market to build a biogas plant, and increased cost of raw materials in rural areas have increased the total production cost of biogas plants. One of the participants suggested that, in the past, households used to get sand and gravels for free from nearby riverbeds to construct a biogas plant. In the past few years, however, these resources that are to be managed by end beneficiaries have become scarce and expensive. As a result, domestic biogas plant is becoming less attractive for its consumers. It is particularly so in the context when more efficient and cheaper technologies are entering the market every day. Therefore, unless the resource efficiency of constructing and operating a biogas plant is improved, subsidy will continue to remain one of the key motivations for rural households to own the current models of biogas plant being promoted in Nepal.

\subsection{Biogas users}

As of May 2018, Nepal has 400,432 domestic and 88 large biogas plants installed across the country. For this study, in-depth interviews were conducted with 15 biogas users in Mandan Deupur and Panchkhal areas of Kavre district. Almost all biogas users interviewed were farmers by profession except one teahouse owner.

\subsubsection{Subsidy for earthquake-affected households}

Many biogas plants built prior to the 2015 earthquake are either partly or fully destroyed in many districts affected by the earthquake. The revised RE Subsidy Policy of 2016 has included a special subsidy provision for the earthquake-hit households. However, majority of the affected biogas users in the study sites were found unaware of the provision, which showed information gap among targeted beneficiaries. Only few (two out of 15 participants) roadside households along the way to Kuntabesi in Mandan Deupur area of Kavre district suggested that they learned about biogas subsidy for earthquake victims on the radio.

\subsubsection{Impact of biogas}

When asked about the benefits of biogas, majority of participants promptly suggested its role in toilet waste management. Almost all biogas users in the study area said that they did not use toilet until a biogas plant was built outside their houses. Many participants associated biogas plants as important parts of their toilet systems.

"We are building another biogas plant for our new house across the street (on the roadside about halfway from Zero Kilo to Kuntabesi) at our own expense. Otherwise, where will our toilet waste go?" - Devaki, Mandan Deupur

On further probing, participants cited other benefits such as clean kitchen, health benefits, its uses as a cooking fuel and a source of fertilizer for their farms. For almost all users, firewood was the primary and the only cooking fuel available to them before the installation of biogas in their kitchens. Some of the frequently cited health benefits by the participants are reduction in eye irritation, headache and coughing. 
Participants who practiced subsistence farming suggested that bio-slurry from their biogas plants, as fertilizer was enough for their farm. Not all users seem to have the same opinion about the adequacy of bio-slurry as fertilizer. However, majority of the biogas users suggested that their land productivity has improved over the years. Participants were mostly unable to state the benefit of biogas in monetary terms.

Only two users interviewed reported that they only used biogas for cooking meals; others used it as a secondary fuel for cooking. Except for one teahouse owner, all participants of this study are local farmers by profession and used biogas cookstove for domestic uses. Many said that the amount of gas the biogas stove emits have decreased over the years, and particularly so after the earthquake.

\subsubsection{Biogas subsidy}

When asked for their perception about biogas subsidy, all participants seemed to have one of the three worldviews as represented by the following quotes:

i) "For those who can afford, they will construct biogas without subsidy. If government provides subsidy, we would seek subsidy. For toilet waste management, biogas technology is important, so we will have to manage even if there is no subsidy." - Sita Bista, Mandan Deupur (commercial farmer)

ii) "If there is no subsidy, people may not want to construct biogas at their own expense." - Saili Danuwar, Mandan Deupur (smallholder farmer)

iii) "Subsidy or not, younger generation may not want to own a biogas plant, as effort is required to produce gas. Younger generation look for smarter technologies, they seek want luxury. Younger generation is less likely to adopt this technology. My younger son came to visit us yesterday from Kathmandu. I asked him to help me carry sludge from the biogas digester to the field. He refused and said he does not want to do it." - Kanchhi Maya, Kuntabesi (smallholder farmer)

Majority of participants said that if their current biogas plants stop working or if they have to build another one for a new house, they would not wait for subsidy. On the other hand, biogas users in more disadvantaged community suggested that they would rather switch to LPG or other easier alternative if there were no subsidy on biogas. For those who said absence of subsidy would not discourage them from installing biogas at their own expense, are the ones who seem to have larger farms and have benefited more from biogas. More rigorous study needs to be done to further explore the underlying factors influencing their perception about subsidy on RETs.

\subsubsection{Information and after-sales services}

Almost all current biogas users said that they learned about the technology through a representative from a biogas company. This suggests that biogas companies play a vital role in the promotion of biogas technology in remote areas. On the other hand, it also allows a room for information asymmetry and that there is limited access to information for consumers to make well-informed decisions around the construction of biogas plants. Few users who live close to the market suggested that they learned about biogas technology from a local agriculture office, or social workers.

Many suggested that after the installation of a biogas plant, and after the warranty period ends, it is difficult to get service providers to visit their houses for repair services. Majority of the biogas users had little knowledge about whom to contact if they wanted to install a new biogas technology, or if anything goes wrong with their existing biogas plants. Although study participants were the key users of biogas, many said that they did not know the total cost of biogas because their husbands or sons made the payments. Regardless of the caste, women were found to have little participation in making the purchase decision of the biogas. This was particularly true for biogas users residing further away from the market area.

\section{Conclusion}

Clearly, renewable energy sector of Nepal has come a long way and has made a significant progress in terms of total RET installations. According to the Economic Survey 2017-2018, more than 3 per cent of the total energy consumed in Nepal is derived through modern renewable energy systems [14]. Many argue that this growth (indicated by total number of installations) in RE sector is driven by RE subsidy [3, 15]. Interestingly, study participants, and other studies have suggested that RE subsidy has primarily benefited better-off households than the low-income populations.

As mentioned earlier in this paper, this study focuses primarily on the impact of RE subsidy in the grass roots with special reference to biogas subsidy. Majority of the stakeholders suggest that biogas should not be treated as any other market goods; it may be difficult to sell biogas technology without subsidy due to high labor, transportation and material costs involved in its construction. The high upfront cost of the technology clearly is one of the biggest barriers in the market-led 
dissemination of biogas technology (particularly the one being promoted by the GoN). This highlights the need for improvement in resource (land, raw material for its construction and operation) and cost efficiency of the technology for it to remain economically viable for farming communities, to whom the technology might have the greatest utility. Many participants also argue that more targeted subsidy and programmes would be necessary to promote biogas technology among lowincome farming communities. Stakeholders' perception about the subsidy reform and its impact in the grass roots, however, seem to vary across stakeholder groups.

A lack of awareness about RET options, multiple benefits of the technology and RE subsidy policies is another important barrier that can limit the effective implementation of RE subsidy policies at the grass roots. As highlighted by this study, many participants whose biogas plants were ruined by the 2015 earthquake were unaware about the subsidy provision targeted at earthquake-affected households. Many also did not have any idea as where to go to seek repair services.

A lack of local availability of biogas technicians has been one of the key hurdles in ensuring sustained use of biogas technology in rural communities. Subsidy delivery mechanism has made a provision of after-sale-service for several years post-installation mandatory for the RE technologies being promoted by the Nepal government. This is a great move to ensure accountability of companies towards their clients. However, it is cumbersome and expensive for rural households to get anything fixed if they have to, after the warranty period ends. Most of the companies that provide RE goods and services to rural areas are based in urban or sub-urban areas, and are often reluctant to provide repair services after the subsidy amount has been disbursed. This gap in RE market system has been one of the major impediments in the adoption and sustained use of RE technologies, particularly in rural areas. Developing local biogas technicians may be an alternative to ensure local availability of repair and maintenance services to rural communities.

Biogas users, primarily women, have been benefitting from biogas technologies in multiple ways. Some of the benefits of the technology identified by the users were: cleanliness, freedom from smoke and its health implications, organic fertilizer for their farms, and toilet and agro-waste management. The majority of the users who said they would install biogas technology regardless of the subsidy provision are also the ones' who have been reaping multiple benefits (such as biogas stove for cooking, toilet waste management, use of bio-slurry as fertilizer) from the technology. Social acceptance of any technology largely depends on the users' perception of the benefit. Therefore, awareness about the benefit and correct use (to ensure maximum benefit) of the technology is important. Without subsidy or some kind of financial intermediation, access of poor farmers to biogas technology is likely to remain a challenge because of its high upfront cost. Better measures and communication strategy are needed to make targeted subsidies and relevant information about policy mandates and provision accessible to the grass roots.

In order to substantiate the finding from this study and for generalizable insight into RE subsidy policy of Nepal, more rigorous research to include all RE technologies covered by the subsidy policy, diverse population, and geographic locations will be necessary.

\section{Acknowledgments}

The research leading to this paper was funded by Energy: Empowering Women, Uplifting Lives Project, an advocacy project implemented by Centre for Rural Technology, Nepal (CRT/N) and International Network on Gender and Sustainable Energy (ENERGIA). The author would like to thank all study participants for their time, insights and cooperation.

\section{References}

[1] W. Mostert, K. Singh, M. Linddal, "Joint Review of Energy Sector Assistance Programme (ESAP II) Nepal”, The Norwegian Agency for Development Cooperation, Oslo, Norway, Rev. Report. 2011.

[2] D. Bhattarai, E. Somanathan and M. Nepal. "Are renewable energy subsidies in Nepal reaching the poor?". Energy for Sustainable Development, vol. 43, p.114, 2018, [Online]. Available:

https://www.sciencedirect.com/journal/energy-forsustainable-development/vol/43/suppl/C. [Accessed Oct. 12, 2018]

[3] M. Adhikari, B.R.Pahari, R. Shrestha, R. "Impact of Renewable Energy Subsidy Policy in Rural Electrification”, In Proc. IOE Graduate Conference 2017, 2017. vol. 5, pp. 15-22.

[4] C. Damgaard, D. McCauley, and J. Long, "Assessing the energy justice implications of bioenergy development in Nepal”. Energy, Sustainability and Society, vol. 7, no. 8, 2017. [Online]. Available:

https://energsustainsoc.biomedcentral.com. [Accessed Oct. 10, 2018]

[5] T. Jamasb, R. Nepal, "Energy sector liberalization: Pricing and Subsidy reform and the poor", In Proc. International Association for Energy Economics, Antalya Special Issue, May 2015. [Abstract]. Available: 
https://www.iaee.org/proceedings/article/12720.

[Accessed Oct. 12, 2018]

[6] Ricardo Energy and Environment, "Renewable Energy for Rural Areas (RERA) Programme Outline". Ricardo Energy and Environment, Tech. Report, 2017.

[7] International Energy Agency. "World Energy Outlook, Looking at Energy Subsidies: Getting the Prices Right", International Energy Agency, Paris, France, 1999.

[8] B. Mainali, and S, Silveira, "Financing off-grid rural electrification: country case Nepal”, Energy, vol. 36, no. 4, p. 2194, 2011. [Online]. Available: https://www.sciencedirect.com/journal/energy/vol/36/issu e/4. [Accessed Oct. 3, 2018]

[9] R. Bacon, E. Ley, M. Kojima, L. Garrido, "Subsidies in the Energy Sector: An Overview", The World Bank Group, Washington, D.C., USA, Tech. Report. 2010.

[10] D.F. Barnes, J. Halpern, "Subsidies and Sustainable Rural Energy Services: Can We Create Incentives Without Distorting Markets?", The World Bank Group, Washington, D.C., USA, Tech. Report, 2000.

[11] National Planning Commission, "Eighth Plan: Unofficial translation". National Planning Commission, Kathmandu, Nepal, 1992, [Online] Available: http://www.npc.gov.np/images/download/eighth_eng.pdf. [Accessed Oct. 3, 2018]

[12] Government of Nepal, "Rural Energy Policy, 2006", Government of Nepal, Kathmandu, Nov. 2006. [Online]. Available: https://www.aepc.gov.np/uploads/docs/ [Accessed Sept. 22, 2018]

[13] Government of Nepal. "Renewable Energy Subsidy Policy, 2073 BS”, Government of Nepal, Kathmandu, Nepal, May 2016. [Online]. Available: https://www.aepc.gov.np/uploads/docs/ [Accessed Oct. 3, 2018]

[14] Nepal Ministry of Finance, "Economic Survey 2017/18". Ministry of Finance, Government of Nepal, Kathmandu, Nepal, Jun. 2018. [Online]. Available: https://mof.gov.np/uploads/document. [Accessed Oct. 12, 2018]

[15] R. Mohideen, "Energy technology innovation in South Asia. Implications for Gender Equality and Social Inclusion", Asian Development Bank, Manila, The Philippines, Tech. Report, 2018, ADB South Asia Working Paper Series. No. 61. 